\title{
Tourist trip design with heterogeneous preferences, transport mode selection and environmental considerations
}

\author{
José Ruiz-Meza ${ }^{1}$ (D) . Jairo R. Montoya-Torres ${ }^{1}$ (D)
}

Accepted: 19 July 2021 / Published online: 6 August 2021

(C) The Author(s), under exclusive licence to Springer Science+Business Media, LLC, part of Springer Nature 2021

\begin{abstract}
Tourism is one of the fastest-growing sectors in the world with a shift from mass tourism to personalized travel. Nevertheless, it generates significant environmental impacts. The current events associated with quarantine measures generated by COVID-19 represent, however, a risk for this sector. It is hence necessary to create strategies that allow efficient decision-making for all echelons and actors for a rapid recovery. Tourists are key actors, which makes necessary to facilitate tourism trip planning according to tourists' preferences as a complex process. In this paper, we propose a novel model of tourist trip planning for heterogeneous preferences in a tourist group and selection of transport modes, in the first instance, while a second step seeks at minimizing the level of $\mathrm{CO}_{2}$ emissions. A comparison of the two models is made considering the objectives associated with individual tourist benefits and group profit equity, in contrast to the inclusion of the cost of $\mathrm{CO}_{2}$ emissions. A numerical comparison is carried out with a total of 546 data sets. Results illustrate the conflict between those objectives by generating an inverse relationship between the individual and group profit equity of tourists, in addition to individual benefit and emission minimization.
\end{abstract}

Keywords Tourist trip design problem · Mathematical modeling · Carbon emissions · Heterogeneous preferences $\cdot$ Transport mode selection $\cdot$ Post-COVID

\section{Introduction}

Before the COVID-19 pandemic (caused by the coronavirus SARS-CoV-2), tourism was considered one of the sectors with the greatest growth prospects worldwide and one of the greatest drivers of economic development in the regions (Daniel et al., 2017), supported by the increase in the number of tourists and the development of the infrastructure of the destinations (Saluveer et al., 2020; WTO, 2019). However, this sector is currently one of the most affected by the COVID-19 pandemic with repercussions for all actors in the supply chain due to the travel ban (Goodell, 2020; Nicola et al., 2020; Samson, 2020). This

Jairo R. Montoya-Torres

jairo.montoya@unisabana.edu.co

1 Facultad de Ingeniería, Universidad de La Sabana, Campus Puente del Común, Km. 7, Autopista

Norte de Bogotá, Chía, Cundinamarca, Colombia 
situation is expected to generate major changes in travel behavior and planning for postpandemic tourism scenarios ( $\mathrm{Li}$ et al., 2020). Therefore, the tourist trip design problem (TTDP) is presented as an alternative solution to the several restrictions that must be considered according to the real contexts of the destinations. The TTDP aims at planning tourist routes for a single tourist or a group of tourists by maximizing the benefit obtained from visiting multiple points of interest (POIs) without exceeding the budget (Gavalas et al., 2015b; Kotiloglu et al., 2017; Liao \& Zheng, 2018; Rodríguez et al., 2012; Vansteenwegen \& Van Oudheusden, 2007; Zheng \& Liao, 2019).

Planning a tourist itinerary is a complex process that involves several variants (Kotiloglu et al., 2017; Liao \& Zheng, 2018). One of these variants that tourists should consider when planning their itinerary is the selection of the mode of transport (Garcia et al., 2009). This process may be affected by the pandemic, guiding tourists to prioritize some types of transport over others ( $\mathrm{Li}$ et al., 2020). Transport takes relevance from the definition of tourism. Indeed, tourism consists of the movement of people or groups of people around a set of different sectors and points of interest (POI) in order to satisfy the preferences of tourists in a destination that the region offers for rest, recreation, among others, within a tourist route (Leiper, 1979; Sedarati et al., 2019). Therefore, transport is an important process that ensures mobility and accessibility between POIs and can even determine the attractiveness of these POIs (Le-Klähn \& Hall, 2015; Van Truong \& Shimizu, 2017).

On the other hand, current conditions lead tourists to consider social distancing in case of traveling in a group with homogeneous or heterogeneous preferences (i.e. within the group tourists prefer to visit the same POIs or each tourist selects specific POIs). The trend in global tourism is the shift from mass travel to customize itineraries that include heterogeneous preferences, even in group travel (Zheng \& Liao, 2019). This variant of the TTDP represents an efficient alternative to be able to distribute the tourists of the group, thus avoiding the total concentration of the number of tourists in each POI and even on the route. However, when constructing the group itinerary, benefits should be achieved for all tourists based on equity (equity in group profit) (Wang, Liu, \& Innes, 2019). In this way, it is intended that the tourists in the group present an equitable benefit despite having heterogeneous preferences and visiting different POIs. These social dimensions remain a challenge in the development of optimization models and in resolving conflicts between the three dimensions of sustainability (environmental, social, and economic) (Fiack et al., 2021; Vega-Mejía et al., 2019).

In addition to the situation generated by COVID-19, there are other problems that can substantially affect tourism. Climate change is one of the issues that is expected to have a significant impact in the coming decades (Scott et al., 2012). This situation has been very little investigated, generating a barrier that avoids determining the consequences for the competitiveness and sustainability of tourism in the regions (Scott et al., 2016, 2019); it is important to emphasize that tourism is also a sector that generates large emissions into the environment (UNWTO, 2012). This drives the sector towards the development of sustainable tourism in accordance with the Sustainable Development Goals (SDGs) (Nguyen et al., 2019). This approach takes relevance in transport as a process that generates high $\mathrm{CO}_{2}$ emissions (Pradenas et al., 2013; Qian \& Eglese, 2016; Sánchez et al., 2013), as do accommodation and other facilities (Sedarati et al., 2019). There are several perspectives to address the issue of environmental impact for tourism; however, within the tourist trips problems only the work of Susanty et al. (2018) refers to this area from $\mathrm{CO}_{2}$ emissions in transport. Therefore, there is a great research opportunity to work on this topic in tourism.

Considering the previous context, this paper addresses the problem of tourism trip planning with heterogeneous preferences of tourists, transport mode selection, and equity in 
group profit. The objectives of the model are associated with the benefit of each tourist, the equitable benefit for the tourist group, and the level of $\mathrm{CO}_{2}$ emissions. This problem is approached in two stages. The first stage presents a bi-objective model for tourism planning with heterogeneous preferences that considers the group equitable profit and transport mode selection. This problem also includes the time windows to access the different POIs. This approach is more realistic in contrast to previous works from the literature (i.e., Malucelli et al., 2015; Sylejmani et al., 2017; Zheng \& Liao, 2019), in the sense that, on the route, the tourist can use different transport modes. This can be translated as a potential scheme to support sustainability (Tawfik \& Limbourg, 2019). Then, the second stage presents the multi-objective model which, in addition to the considerations of the previous both objectives, the minimization of $\mathrm{CO}_{2}$ emissions is added as a third optimization objective. This approach is guided by the new trend of sustainable tourism that the World Tourism Organization and the SDGs are aiming (Nepal et al., 2019).

As pointed out later in the literature review, there is no evidence of a problem that considers these three aspects in an articulated manner (i.e., heterogeneous preferences, transport mode selection, and $\mathrm{CO}_{2}$ emissions). Therefore, this paper proposes novel mathematical models to approach the current conditions of tourism development in times of the pandemic and post-pandemic under these three aspects.

The remainder of this paper is structured as follows. Section 2 presents a literature review about the tourist trip design problem with heterogeneous preferences, transport mode selection and sustainability in the construction of tourist paths. Section 3 presents the proposed mathematical models, while their application is presented in Sect. 4 through an illustrative example. Section 5 presents the results of the experimental evaluation and comparison of the models. Finally, Sect. 6 summarizes the conclusions and outlines some opportunities for future research.

\section{Literature review}

Tourist trip planning requires information about potential places according to the tourist's preferences, available budget, time to visit each point of interest (POI), travel times, mode of transport, among others, that make it a complex process and difficult to solve mathematically (Kotiloglu et al., 2017). In the academic literature, this problem is called the Tourist Trip Design Problem (TTDP) (Brito et al., 2017; Vansteenwegen \& Van Oudheusden, 2007), whose aim is to plan the tourist's or group's itinerary taking into account time or economic budget constraints (Gavalas et al., 2015b; Kotiloglu et al., 2017; Liao \& Zheng, 2018; Rodríguez et al., 2012; Vansteenwegen \& Van Oudheusden, 2007; Zheng \& Liao, 2019).

The great interest of the TTDP has attracted the attention of researchers, as witnessed by the amount of literature reviews published since 2009 (Gavalas et al., 2014; Gunawan et al., 2016; Lim et al., 2019; Ruiz-Meza \& Montoya-Torres, 2020; Shcherbina \& Shembeleva, 2014; Souffriau \& Vansteenwegen, 2010; Vansteenwegen et al., 2009). Throughout the literature, tourism planning problems have been modeled through Operations Management/Operational Research techniques under several approaches, such as the Cruise Itinerary Problem (Leong \& Ladany, 2001), the One-Period Routing Bus Problem (BTP) (Deitch \& Ladany, 2000, 2001), the City Bus Tour Problem (CTB) (Bagloee et al., 2017), the Generalized Maximum Coverage Problem (GMC) (Brilhante et al., 2013, 2015), the Optimal Tourist Problem (OTP) (Yu et al., 2015), and the Orienteering problem (OP) 
(Vansteenwegen \& Van Oudheusden, 2007). This last together with the Team Orientering Problem (TOP) are the most emplyed modeling appraoches (Ruiz-Meza \& Montoya-Torres, 2020; Shcherbina \& Shembeleva, 2014; Vansteenwegen \& Van Oudheusden, 2007).

The OP can be considered as a selective routing problem that aims to determine the order and set of nodes to be visited in order to maximize the benefit received without exceeding the time budget (Gunawan et al., 2016; Kara et al., 2016). When several routes are to be defined, a TOP is considered more efficient. The main objective of the TOP is to maximize profit by selecting and visiting a set of nodes, where the start and end nodes are fixed. The TOP selects several routes at once, so the OP can be considered as a singleroute version (Vansteenwegen, 2009). In this sense, the TOP can be approached as a multilevel optimization problem, starting with a selection of the set of nodes to be visited. Then, the assignment of scores to each team member is made and finally, the construction of the routes is carried out (Chao et al., 1996). The Team Orienteering Problem with Time Window (TOPTW) is the most appropriate extension of the TOP to describe the TTDP because, generally, the POIs have an opening time window (Expósito et al., 2019a; Gavalas et al., 2014).

Several variants are considered when modeling real problems (Ruiz-Meza et al., 2020), such as time windows (Garcia et al., 2009; Souffiau et al., 2009), time-dependency (Garcia et al., 2010a, 2010b), arc score (Arc Orienteering Problem -AOP) (Verbeeck et al., 2014), arc and POI scores (Mixed OP-AOP) (Gavalas et al., , 2016, 2017; Malucelli et al., 2015), multi-commodity (Malucelli et al., 2015), multiple periods (Kotiloglu et al., 2017), timebased user interest (Lim et al., 2017) multiple constraints (Sylejmani et al., 2012), heterogeneous preferences (Malucelli et al., 2015; Zheng \& Liao, 2019), uncertain travel times (Hasuike et al., 2013), previous tourist experiences (Zheng et al., 2017), time-dependent stochasticity (Liao \& Zheng, 2018), hotel selection (Zheng et al., 2020), electric vehicles (EV) for tourism (Wang et al., 2018), scores and travel fuzzy times (Expósito et al., 2019a, 2019b), and Clustered POIs, when POIs of different types of tourism are identified and grouped according to their class (Expósito et al., 2019a).

In addition, another relevant but little-studied variant is the type of tourism associated with urban environments. This type of tourism is gaining relevance due to the growth of cities and their attractiveness as tourist sites for business activities, shopping, medical purposes, and visits to family and friends, among other activities (Yuan et al., 2018). The complexity of urban tourism is mainly generated in the urban logistics management associated with the problems arising from transportation in urban areas (Zheng \& Liao, 2019; Zheng et al., 2020). Therefore, as in urban logistics, it is necessary to consider variants associated with travel time, vehicle congestion, and, above all, the reduction of $\mathrm{CO}_{2}$ emissions (De Marco et al., 2017). However, the TTDP, whether in urban or non-urban environments, focuses on the movement of people, while in urban logistics the urban transport of goods is the main focus (Morana, 2014).

Since the current paper studies a problem with heterogenous preferences, time windows and environmental impact $\left(\mathrm{CO}_{2}\right.$ emissions), following subsections present a review of the variants that are included in such a problem. A summary of this literature is presented in Table 1.

\subsection{Heterogeneous preferences}

About TTPD with heterogeneous preferences, the literature is very limited. Malucelli et al. (2015) proposed a new combinatorial optimization problem called the Multi-Commodity 
Table 1 Previous works on the TTDP with heterogeneous preferences, transport mode selection, and consideration of $\mathrm{CO}_{2}$ emissions

\begin{tabular}{llll}
\hline References & $\begin{array}{l}\text { Heterogeneous } \\
\text { preferences }\end{array}$ & $\begin{array}{l}\text { Transport mode } \\
\text { selection }\end{array}$ & $\mathrm{CO}_{2}$ emissions \\
\hline Malucelli et al. (2015) & $\mathrm{X}$ & & \\
Sylejmani et al. (2017) & $\mathrm{X}$ & & \\
Zheng and Liao (2019) & $\mathrm{X}$ & $\mathrm{X}$ & \\
Abbaspour and Samadzadegan (2009) & & $\mathrm{X}$ & \\
Abbaspour and Samadzadegan (2011) & & $\mathrm{X}$ & \\
Garcia et al., (2010a, 2010b) & & $\mathrm{X}$ & \\
Garcia et al. (2013) & & $\mathrm{X}$ & \\
Gavalas et al. (2015a) & & $\mathrm{X}$ & $\mathrm{X}$ \\
Gavalas et al. (2015b) & & $\mathrm{X}$ & $\mathrm{X}$ \\
Wu et al. (2017) & & $\mathrm{X}$ & \\
Yu et al. (2017) & & $\mathrm{X}$ & \\
Liao and Zheng (2018) & $\mathrm{X}$ & & \\
Susanty et al. (2018) & & & \\
This paper & & & \\
\hline & & &
\end{tabular}

Orienteering Problem with Network Design (MOP-ND). Their approach satisfies the individual preferences of a group of tourists with the same origin-destination, maximizing the profit of each tourist. These authors used real data from Trebon region in South Boemia for cycle tourist. Sylejmani et al. (2017) developed an extension of the TTDP that considers group planning with personalized interests and mutual relationship between different tourists. The model is based on the Multi Constraint TOPTW to consider the case of multiple trips with multiple tours (MCMTOPTW). The problem is solved by a taboo search algorithm with a neighborhood structure based on three unique operators: Separate, Join and Insert. Finally, Zheng and Liao (2019) developed a bi-objective model for planning group tourist trips considering heterogeneous preferences. The first objective maximizes the fairness of individual members, while the second objective maximizes the total group utility. The problem is solved by a non-dominated classification algorithm (NSACDE) that combines ant colony optimization (ACO) and the differential evolution algorithm (DEA). The algorithm was tested with real data from Kulangsu located in China.

\subsection{Transport mode selection}

Tourism is based on the resource, service, and infrastructure capacities offered by the territory, and in terms of infrastructure and networks, access must be guaranteed for the flow of people and goods (Millán, 2010). Therefore, transport is a process of great importance for the accessibility of the POIs and to define to some degree the attractiveness of these sites (Le-Klähn \& Hall, 2015; Van Truong \& Shimizu, 2017). Transport is one of the sectors responsible for the operation and development of tourism (Chaudhari \& Thakkar, 2019). In addition, transport is included in the TTPD for the flow of tourists (Gavalas et al., 2015a) considering travel time, transport mode, among other aspects that can be associated with transport (Garcia et al., 2009). 
Abbaspour and Samadzadegan (2009) applied a genetic algorithm to solve the problem of planning tourist trips considering the travel time in a multimodal transport network. For the model, monomodal (use of only one type of transport mode in the trip) and multimodal (combination of different transport modes) routes was considered. The test database was from Tehran, Iran. Subsequently, Abbaspour and Samadzadegan, (2011) applied two genetic algorithms to solve the tour planning problem with multimodal transport in urban environments. Garcia et al., (2010a, 2010b) develop a hybrid approach to solve the Time Dependent Team Orienteering Problem with Time Windows (TD-TOPTW) including public transport. Garcia et al., (2013) developed two solution algorithms for the TDTOPTW considering public transport as a decision-making tool in real time in the Personalized Electronic Tourist Guides (PETs). Gavalas et al. (2015a) include the eCOMPASS application that allows the calculation of tourist trips considering the multimodal and urban transport based on a TDTOPTW. To solve the problem an algorithm called SlackRoutes was developed. Gavalas et al. (2015b) developed The Time Dependent CSCRoutes (TD_CSCR) and The Time Dependent Slack CSCRoutes (TD_S $\ell$ CSCR) which are extensions of Cluster Search Cluster Ratio (CSCRatio) and Cluster Search Cluster Routes (CSCRoutes). The new algorithms allow managing time-dependent travel times between different POIs, to solve the problem of TDTOPTW with which the periodicity of transit services is not assumed. Wu et al. (2017) propose a tourist planning model to maximize the tourist utility denoted as the tourist experience. Tourist preferences for the attraction, the transport mode used between each POI, attraction attributes, time and cost budget were considered. Yu et al. (2017) propose a Multi-Modal Team Orienteering Problem with Time Window (MMTOPTW) for the development of a tourist trip design application with several transport modes to be chosen by the tourist.

In addition, other time-dependent work has been developed on tourist itineraries with transport mode selection. Liao and Zheng (2018) develop a model based on a stochastic OP that aims at designing more realistic and personalized routes for each tourist. The problem considers spatial-temporal structures and mode selection between POIs (i.e. the tourist can select the mode of transport considering the time constraints, preferences, and availability). To solve the problem a hybrid heuristic algorithm based on random simulation (RSH2A) is applied.

\section{$2.3 \mathrm{CO}_{2}$ emissions}

Tourism is one of the major contributors to pollution problems (Susanty et al., 2018; UNWTO, 2012) as is the transport sector (Bai et al., 2017; Pradenas et al., 2013; Qian \& Eglese, 2016; Sánchez et al., 2013). This is a serious concern worldwide because of the gradual increase of $\mathrm{CO}_{2}$ emissions and their environmental impact (Almouhanna et al., 2020; Juan et al., 2016; Muñoz-Villamizar et al., 2017, 2019). However, the application of environmental practices by companies in the tourism sector can generate improvements in operational performance, and minimize energy consumption (Perramon et al., 2014; Zeng et al., 2010). Therefore, many studies have been developed to minimize $\mathrm{CO}_{2}$ emissions in the routing process (Marrekchi et al., 2021). In the field of tourism and itinerary design, however, this problem is addressed only by Susanty et al. (2018), where a dynamic programming approach is applied to find the shortest routes in the tourist trip to minimize $\mathrm{CO}_{2}$ emissions.

For a sustainable tourism, sustainable transportation is necessary (Le-Klähn \& Hall, 2015). Filimonau et al. (2014) suggest that tourists should avoid cars and air travel to 
minimize $\mathrm{CO}_{2}$ emissions and seek to use cleaner transportation systems such as public transport networks. However, public transport systems are not sustainable systems worldwide. Therefore, the use of intermodal transport can be considered as a contribution to sustainability for tourism (Tawfik \& Limbourg, 2019). As pointed out before, this last is one of the contributions of the current paper.

\section{Proposed models}

The mathematical approach, which is divided into two stages, is detailed below. The first stage presents a TTDP based on a team orienteering problem with time windows (TOPTW) for heterogeneous preferences in tourist groups and transport mode selection between arcs. Subsequently, the model with $\mathrm{CO}_{2}$ minimization is detailed.

\subsection{TTDP with time windows, heterogeneous preferences, and selection of transport mode}

The mathematical model for tourist trip planning with heterogeneous preferences in tourist groups and selection of transport modes is detailed next.

Sets

$I$ set of POIs $\{1,2,3, \ldots, i\}$

$K$ set of routes $\{1,2,3, \ldots, k\}$

$U$ set of tourists $\{1,2,3, \ldots, u\}$

$L$ set of transport modes $\{1,2,3, \ldots, l\}$

$I^{0}$ Depot node $\{0\}$

\section{Parameters}

$P_{i u}$ profit in each POI for the tourist, $\forall i \in I \backslash\{0\}, \forall u \in U$

$v_{i}$ visiting time for each POI, $\forall i \in I \backslash\{0\}$

$\left[a_{i}, b_{i}\right]$ time window in each POI, $\forall i \in I \backslash\{0\}$

$d_{i j}$ travel distance between POIs, $\forall i j \in I$

$Q_{k}$ maximum number of tourists on each route, $\forall k \in K$

$Q m_{k}$ minimum number of tourists on each route, $\forall k \in K$

$T_{M a x}$ maximum time budget for the tourist, $\forall u \in U$

$\mathrm{Vel}_{l}$ average speed for each transport mode, $\forall l \in L$

$V c_{i j l}$ variable cost for each transport mode, $\forall i j \in I, \forall l \in L$

$P i_{u}$ maximum transportation budget, $\forall u \in U$

$t_{i j l}$ travel time for each transport mode, $\forall i j \in I, \forall l \in L$

\section{Variables}

$X_{i j k}=1$ if route $k$ goes from $i$ to $j$, and $X_{i j k}=0$ otherwise, $\forall i j \in I: i \neq j, \forall k \in K$

$Y_{i k}=1$ if POI $i$ is included in route $k$, and $Y_{i k}=0$ otherwise, $\forall i \in I \backslash\{0\}, \forall k \in K$

$W_{i j k u}=1$ if tourist $u$ goes from $i$ to $j$ in route $k$, and $W_{i j k u}=0$ otherwise, $\forall i j \in I: i \neq j, \forall k \in K, \forall u \in U$

$\delta_{i k u}=1$ if POI $i$ is included in route $k$ for tourist $u$, and $\delta_{i k u}=0$ otherwise, $\forall i \in I \backslash\{0\}, \forall k \in K, \forall u \in U$ 
$Z_{i j k u l}=1$ if tourist $u$ goes from $i$ to $j$ in route $k$ with transport mode $l$, and $Z_{i j k u l}=0$ otherwise,

$\forall i j \in I: i \neq j, \forall k \in K, \forall u \in U, \forall l \in L$

$G_{k}=1$ if route $k$ is used, and $G_{k}=0$ otherwise, $\forall k \in K$

$T_{i k u}$ : non-negative variable representing the time arrival in each POI $i$ for tourist $u$ in route $k$, $\forall i \in I \backslash\{0\}, \forall k \in K, \forall u \in U$

$T R_{u}$ nonnegative variable; Travel time for the tourist $u, \forall u \in U$

Max: maximum profit

Min: minimum profit

Bi-objective function

$$
\text { Maximize } Z=\alpha \sum_{i=1}^{I} \sum_{k}^{K} \sum_{u}^{U} P_{i u} \delta_{i k u}+\beta(- \text { Max }+ \text { Min })
$$

Subject to:

$$
\begin{gathered}
\sum_{j=1}^{J} X_{i j k}=\sum_{j=1}^{J} X_{j i k} \forall i \in I^{0}, \forall k \in K \\
\sum_{j=1}^{J} W_{i j k u}=\sum_{j=1}^{J} W_{j i k u} \forall i \in I^{0}, \forall k \in K, \forall u \in U \\
\sum_{j=1}^{J} X_{i j k}=G_{k} \forall i \in I^{0}, \forall k \in K \\
\sum_{k}^{K} Y_{i k} \leq 1 \forall i \in I \backslash\{0\}, \forall k \in K \\
\sum_{i=1, i \neq h}^{I} X_{i h k}=\sum_{j=1, j \neq h}^{J} X_{h i k}=Y_{h k} \forall h \in I, \forall k \in K \\
\sum_{i=1, i \neq h}^{I} \sum_{i h k u}=\sum_{j=1, j \neq h}^{J} W_{h i k u} \leq Y_{i k} Q_{k} \forall i \in I \backslash\{0\}, \forall k \in K \\
\sum_{u}^{U} W_{i j k u} \leq X_{i j k} Q_{k} \forall i \in I, \forall j \in I \backslash\{0\}: i \neq j, \forall k \in K \\
\sum_{i n k}, \forall k \in K, \forall u \in U
\end{gathered}
$$




$$
\begin{aligned}
& \sum_{j=1}^{J} \sum_{k}^{K} W_{i j k u} \leq 1 \forall i \in I^{0}, \forall u \in U \\
& \sum_{u}^{U} W_{i j k u} \geq Q m_{k}-M\left(1-X_{i j k}\right) \forall i \in I^{0}, \forall u \in U \\
& \sum_{l}^{L} Z_{i j k u l}=W_{i j k u} \forall i \in I, \forall j \in I \backslash\{0\}: i \neq j, \forall k \in K \\
& \sum_{l}^{L} Z_{i j k u l} \leq 1 \forall i j \in I: i \neq j, \forall k \in K \\
& T_{j k u} \geq \sum_{l}^{L} t_{i j l} Z_{i j k u l}-M\left(1-W_{i j k u l}\right) \forall i \in I^{0}, \forall j \in I \backslash\{0\}, \forall k \in K, \forall u \in U \\
& T_{i k u}+v_{i}+\sum_{l}^{L} t_{i j l} Z_{i j k u l}-T_{j k u} \leq M\left(1-W_{i j k u l}\right) \forall i j \in I \backslash\{0\}: i \neq j, \forall k \in K, \forall u \in U \\
& T R_{u} \geq T_{i k u}+v_{i}+\sum_{l}^{L} t_{i j l} Z_{i j k u l}-M\left(1-W_{i j k u l}\right) \forall i \in I, \forall j \in I \backslash\{0\}, \forall k \in K, \forall u \in U \\
& T R_{u} \leq \operatorname{TMax}_{u} \forall u \in U \\
& a_{i} \delta_{i k u} \leq T_{i k u} \leq b_{i} \delta_{i k u} \forall i \in I \backslash\{0\}, \forall k \in K, \forall u \in U \\
& \operatorname{Max} \geq \sum_{i=1}^{I} \sum_{k}^{K} P_{i u} \delta_{i k u} \geq \operatorname{Min} \forall u \in U \\
& \sum_{i \neq j}^{I} \sum_{j \neq i}^{J} \sum_{k}^{K} \sum_{l}^{L} Z_{i j k u l} V c_{i j l} \leq P i_{u} \forall u \in U \\
& X_{i j k}, W_{i j k u}, Y_{i k}, \delta_{i k u}, Z_{i j k u l}, G_{k} \in\{1,0\} \forall i j \in I, \forall k \in K, \forall u \in U, \forall l \in L \\
& T_{i k u}, T R_{u}, \operatorname{Max}, \operatorname{Min} \geq 0 \forall i \in I, \forall k \in K, \forall u \in U
\end{aligned}
$$

Equation (1) models the bi-objective function, where $\alpha$ and $\beta$ are the weights that decision-makers can assign to either objectives, as follows. The first function corresponds to the benefit of each tourist, while the second function ensures equitable profit for the tourism group. Constraints (2) and (3) ensure the start and end of each route at point 0 . Constraints (4) determine the use of the routes. Constraints (5) ensure that a POI belongs to 
a specific route. Constraints (6) and (7) ensure the flow and continuity of the route. Constraints (8) and (9) ensure that the maximum capacity of tourists in an route is not violated. Constraints (10) ensure that each tourist can belong to only one route. Constraints (11) states that, if an arc is included in a route, at least one tourist must be assigned. Constraints (12) and (13) ensures that only one transport mode is used per tourist in each arc. Constraints (14) and (15) calculates the arrival time at each POI. Constraints (16) calculate the route time of each tourist. Constraints (17) ensure that each tourist's time budget is not exceeded. Compliance with time windows is guaranteed by the Constraints (18). Constraints (19) obtain maximum and minimum profits from tourists. Constraints (20) ensure that the travel cost budget is not exceeded. Finally, the domain of decision variables is summarized in Constraints (21) and (22).

\subsection{Consideration of $\mathrm{CO}_{2}$ emissions}

Based on the mathematical model in Sect. 3.1, the level of $\mathrm{CO}_{2}$ emissions generated by transportation is added. Equation (23) is added as a third objective function. Emissions costs per unit of kilometers traveled in arc $i j$ on each route $k$ by transport mode $l$ are considered and minimized. The following parameters are added: $\mathrm{CO}_{2}$ emissions per distance traveled in each arc $i j$ and mode of transport $l$ is denoted as $C O 2_{i j l}$, the cost of emissions is denoted by $c e$, while the profit-to-cost conversion parameter is denoted as $\varphi$. Similarly, the variable $\varpi_{i j k l}$ is added, where $\varpi_{i j k l}$ is a integer variable denoting the number of tourists traveling through the arc $i j$ of route $k$ using transport mode $l, \forall i j \in I: i \neq j, \forall k \in K, \forall l \in L$

$$
\sum_{i}^{I} \sum_{j}^{J} \sum_{k}^{K} \sum_{l}^{L} C O 2_{i j l} c e \varpi_{i j k l}
$$

The complete model is presented next:

Multi-objective function

$$
\text { Maximize } Z=\alpha \sum_{i=1}^{I} \sum_{k}^{K} \sum_{u}^{U} P_{i u} \delta_{i k u} \varphi+\beta(-\varphi M a x+\varphi M i n)+\gamma\left[-\sum_{i}^{I} \sum_{j}^{J} \sum_{k}^{K} \sum_{l}^{L} C O 2_{i j l} c e \varpi_{i j k l}\right]
$$

Subject to:

Constraints (2)-(22)

$$
\begin{gathered}
\sum_{u}^{U} Z_{i j k u l}=\varpi_{i j k l} \forall i j \in I: i \neq j, \forall k \in K, \forall l \in L \\
\sum_{i=1}^{I} \sum_{k}^{K} \sum_{u}^{U} W_{i j k u}=U \forall j \in I^{0} \\
\varpi_{i j k l} \geq 0 \forall i j \in I, \forall k \in K, \forall l \in L
\end{gathered}
$$

The multi-objective function (24) aims to maximize individual tourist profits, equity in group profit, and minimize the costs of emissions. Parameter $\gamma$ is added to represent the weight given by decision-maker to the computation of $\mathrm{CO}_{2}$ emissions in the objective 
function. The model requires the use of previously explained Constraints (2)-(22). Constraints (25) calculates the number of tourists using mode of transport $l$ in arc $i j$. Constraints (26) ensure that all tourists are assigned to the open routes. Finally, Constraints (27) define the domain of the variable.

\section{An illustrative example}

To develop an example that illustrates the problem and the solution of the mathematical modeling, we built some random instances that will be detailed later. An example of an application is presented for which an instance was considered with 21 POIs, including the starting point, six tourists, three route options, and three modes of transport (car, bus, and walking). The data were applied for the first and second modeling. The results obtained are shown in Figs. 1 and 2.

Initially, we show the route planning for the first model that considers individual, group benefits and transport mode selection. The selected solution corresponds to the criteria weights $\alpha=0.7 ; \beta=0.3$, which present a total of 15 POIs visited by tourists, individual benefits that add up to a score of 587.5 and 75 points of difference between the maximum and minimum score obtained (group profit equity). As shown in Fig. 1, two routes were generated. The first route corresponds to the sequence $0-5-19-10-20-18-14-0$ assigned to tourists 1,4 , and 6 . However, in POI 10, tourist 6 returns to the starting point while tourists 1 and 4 continue the tour by visiting the remaining POIs in the sequence. In the first arc (0-5), two transport modes are used (car and bus). Only the first mode of transport is used for the rest of the arcs. The second route assigned to tourists 2, 3, and 5 presents the sequence 0-11-68-3-7-12-9-4-0. In POI 12, tourist 3 returns to the starting point. Similarly, in POI 9, tourist 2 returns to the starting point. In this route, the three transport modes are used.

The planning of the second model that considers the minimization of $\mathrm{CO}_{2}$ emissions, presents a total of 13 POIs visited through 3 routes. The criteria weights of the selected solution correspond $\alpha=0.7 ; \beta=0.2 ; \gamma=0.1$ with accumulated individual benefits of 428 ,

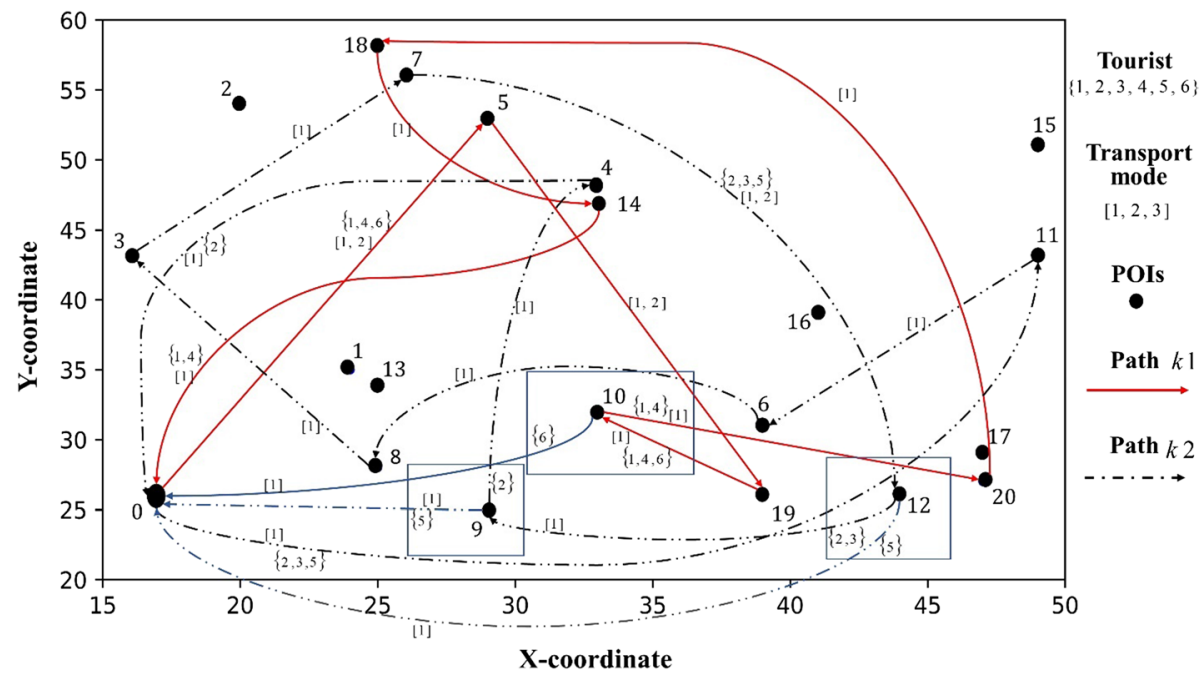

Fig. 1 Paths obtained for the first model with hptoptw-j21b instances 


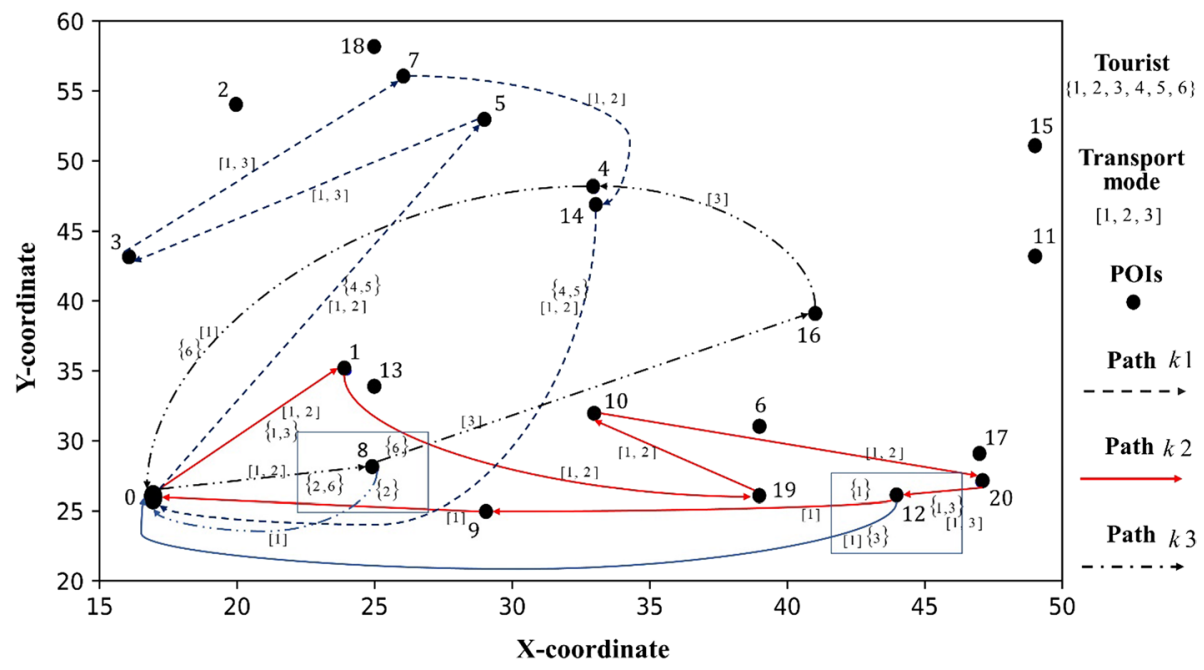

Fig. 2 Paths obtained for the second model with hptoptw-j21b instances

group difference of 99 points and costs of $\$ 856.66$ per $\mathrm{CO}_{2}$ emitted. The first route made by tourists 4 and 5 has the sequence $0-5-3-7-14-0$, with the use of the three modes of transport. The second route made by tourists 1 and 3 has the sequence $0-1-19-10-20-12-9-0$. However, in POI 12, tourist 3 returns to the starting point while tourist 1 continues the route sequence. Only transport modes 1 and 2 (car and bus) are used. Finally, the third route with sequence $0-8-16-4-0$ is made by tourists 2 and 6 . In POI 8 , tourist 2 returns to the starting point. Three modes of transport were used on the route.

\section{Computational experiments}

Proposed models were coded using GAMS (General Algebraic Modeling System) and solved using the solver CPLEX on a computer with 20 GB of RAM, an Intel Core i7-8565U CPU@ $1.8 \mathrm{GHz}$, a 1-TB hard drive and a 64-bit operating system. The model was tested with a set of small randomly generated instances and programming a maximum execution time of two hours.

\subsection{Description of test data sets}

Due to the lack of testing instances according to our review of models that consider tourist preferences, in addition to the lack of small-sized instances for accurate testing of team orienteering problem with time windows models, we built for this work a set of randomly generated data sets based on the instances for TOPTW-MV presented in ( Lin \& Yu, 2017). A total of 14 instances was built as shown in Table 2. The unit costs of transportation were established in $\$ 20, \$ 10$, and $\$ 3$ and budgets associated with transportation were determined for each tourist at $\$ 5000, \$ 5000, \$ 5000, \$ 6000$, $\$ 7000, \$ 4000, \$ 5000$, and \$5000. The maximum time budget $\operatorname{TMax}_{u}$ available for each 
Table 2 Overview of the three groups of instances

\begin{tabular}{llllll}
\hline Instances & Quantity & Number of paths- $k$ & $\begin{array}{l}\text { Number of } \\
\text { vertices- } i\end{array}$ & Number of tourist- $u$ & $\begin{array}{l}\text { Number of } \\
\text { transport } \\
\text { mode- } l\end{array}$ \\
\hline hptoptw-j11 & 5 & $\mathrm{a}, \mathrm{b}, \mathrm{c}, \mathrm{d}=2 ; \mathrm{e}=3$ & 11 & $\mathrm{a}, \mathrm{b}=5 ; \mathrm{c}, \mathrm{d}=6 ; \mathrm{e}=7$ & 3 \\
hptoptw-j16 & 5 & $\mathrm{a}, \mathrm{b}, \mathrm{c}, \mathrm{d}=3 ; \mathrm{e}=4$ & 16 & $\mathrm{a}, \mathrm{b}=6 ; \mathrm{c}, \mathrm{d}=8 ; \mathrm{e}=7$ & 3 \\
hptoptw-j21 & 4 & $\mathrm{a}, \mathrm{b}, \mathrm{c}, \mathrm{d}=3$ & 21 & $\mathrm{a}, \mathrm{b}=6 ; \mathrm{c}, \mathrm{d}=7$ & 3 \\
\hline
\end{tabular}

tourist corresponds to $900,1100,800,850,900,500,900$, and $600 \mathrm{~min}$. The instances are available at the following webpage https://jrmontoya.wordpress.com/research/insta nces/.

\subsection{Model with heterogeneous preferences and transport mode selection}

For the first model, we performed a total of 28 initial tests to obtain general solutions for each proposed objective (i.e., weights of $\alpha=1 ; \beta=0$ and $\alpha=0 ; \beta=1$ for each instance). With the assignment of values $\alpha=0 ; \beta=1$ to the objectives, no results were obtained within the running time limit. The individual benefit corresponds to the maximization of the sum of the benefits obtained for each tourist. The equity in group profit corresponds to the minimization of the difference between the maximum and minimum profit obtained on the route. The results for weights $\alpha=1 ; \beta=0$ are shown in Table 3 . These results show the optimal value of the instance and will be a reference for comparison with the solutions obtained with the variations of the weights of each objective.

Table 3 Overall results for maximizing tourist profits

\begin{tabular}{lllllll}
\hline Instances & Individual profit & $\begin{array}{l}\text { Group profit } \\
\text { equity }\end{array}$ & $\begin{array}{l}\mathrm{N}^{\circ} \text { nodes } \\
\text { visited }\end{array}$ & $\begin{array}{l}\text { Solution } \\
\text { time }(\mathrm{min})\end{array}$ & $\begin{array}{l}\mathrm{N}^{\circ} \text { used } \\
\text { transport }\end{array}$ & $\mathrm{N}^{\circ}$ paths \\
\hline hptoptw-j11a & 349.5 & 82 & 9 & 0.15 & 2 & 2 \\
hptoptw-j11b & 352 & 58 & 9 & 0.16 & 2 & 2 \\
hptoptw-j11c & 279.5 & 59 & 8 & 0.14 & 2 & 2 \\
hptoptw-j11d & 373.5 & 48 & 9 & 0.14 & 1 & 2 \\
hptoptw-j11e & 341 & 76 & 10 & 0.16 & 3 & 3 \\
hptoptw-j16a & 536.5 & 140 & 13 & 0.24 & 2 & 2 \\
hptoptw-j16b & 492.5 & 120 & 12 & 1.14 & 2 & 2 \\
hptoptw-j16c & 468.5 & 90 & 11 & 0.21 & 2 & 3 \\
hptoptw-j16d & 534 & 120 & 13 & 2.15 & 2 & 3 \\
hptoptw-j16e & 635 & 135 & 15 & 3.26 & 2 & 3 \\
hptoptw-j21a & 740.5 & 155 & 20 & 1.53 & 2 & 2 \\
hptoptw-j21b & 620.5 & 150 & 15 & 4.23 & 2 & 2 \\
hptoptw-j21c & 749 & 150 & 18 & 61.03 & 3 & 2 \\
hptoptw-j21d & 695 & 150 & 16 & 9 & 1 & 3 \\
\hline
\end{tabular}




\subsection{Considering $\mathrm{CO}_{2}$ emissions in the model}

In addition, the $\mathrm{CO}_{2}$ emissions by mode of transport and passenger for each kilometer traveled are as follows: taxi $0.14886 \mathrm{~kg} \mathrm{CO}_{2} /$ passenger-km, bus average $0.10391 \mathrm{~kg} \mathrm{CO}_{2} /$ passenger-km, motorcycle $0.11314 \mathrm{~kg} \mathrm{CO} / \mathrm{km}$, and car average $0.18014 \mathrm{~kg} \mathrm{CO} / \mathrm{km} . \mathrm{CO}_{2}$ values associated with public transport (taxi and bus) are calculated on a single passenger basis according to the Department for Business, Energy and Industrial Strategy (2019). The value of car emissions is obtained based on the average emissions of vehicles in different market segments (only $\mathrm{CO}_{2}$ emissions are considered in our study, without considering other gases such as $\mathrm{CH}_{4}$ and $\mathrm{N}_{2} \mathrm{O}$ ). This choice is in line with the statements of Bektaş and Laporte (2011) and Susanty et al. (2018); this last is the only one that includes these emissions in tourism, to our knowledge. So, in developing the model, the decision-maker divides the car emissions by five average occupants. The calculation allows obtaining the emissions per passenger transported, considering that the number of passengers affects fuel consumption.

The average costs per $\mathrm{kg}$ of $\mathrm{CO}_{2}$ are $€ 0.02241$ (SENDECO2, 2020). For the initial tests of the model we assigned the weights $\alpha=1 ; \beta=0 ; \gamma=0, \alpha=0 ; \beta=1 ; \gamma=0$ y $\alpha=0 ; \beta=0$; $\gamma=1$ generating a total of 42 tests. With the assignment of values $\alpha=0 ; \beta=1 ; \gamma=1$ to the objectives, the solution time limit was exceeded in the instances hptoptw-j11e, hptoptw-j16 [a, b, d, and e], and hptoptw-j21 [a, b, and d] with a 100\% gap. The instances hptoptw-j21 [a and c] did not generate a solution for the assignments $\alpha=1 ; \beta=0 ; \gamma=0$, besides the instances hptoptw-j16e and hptoptw-j21d exceeded the assigned time with a gap of $6.89 \%$ and $25.46 \%$, respectively. Which confirms the computational complexity. The rest of the solutions detailing the optimal value of the instances is shown in Table 4.

\subsection{Comparison of results}

The complete set of results is available at https://jrmontoya.wordpress.com/research/insta nces/. Within the set of instances created, hptoptw-j11e, hptoptw-j16e, and hptoptw-j21d are the most complex due to the increase in the number of routes and tourists. We selected these instances to show the graphical behavior of the solutions as a function of the Pareto frontier for the first and the second model (see Fig. 3). In the first model, an inverse behavior of the two objectives is generated. As the individual benefit of tourists increases, the value of the difference between the profit of each tourist increases (i.e., the gap between the highest and lowest profit obtained by a tourist increases). Therefore, the equity in the group profit decreases. Figure 4 shows a two-by-two comparison of the three objectives of the hptoptw-j21a instance to detail the behavior of the solutions and the Pareto frontiers. In addition to the behavior described between the first and second objectives, the Pareto frontier obtained in the second model denotes a directly proportional behavior between the first and third objectives. As the individual profit increases, the amount of emissions increases. Therefore, the objectives conflict because the model aims to maximize the former and minimize the latter. A total of 476 tests was performed corresponding to 13 tests (combinations of the weights of the objectives) for the first model and 21 tests for the second model, for each of the 14 instances.

Comparing the results of the models, an influence on the solutions can be seen by the inclusion of the third objective. This objective forces the model to decrease the POIs visited, generally increasing the number of routes and the computational response time. 
Table 4 Overall results for maximizing benefits and minimizing emissions

\begin{tabular}{|c|c|c|c|c|c|c|c|c|}
\hline Instances & $\begin{array}{l}\text { Main } \\
\text { objec- } \\
\text { tive }\end{array}$ & $\begin{array}{l}\text { Individual } \\
\text { profit }\end{array}$ & $\begin{array}{l}\text { Group } \\
\text { profit } \\
\text { equity }\end{array}$ & $\mathrm{CO}_{2}$ costs & $\begin{array}{l}\mathrm{N}^{\circ} \\
\text { nodes } \\
\text { visited }\end{array}$ & $\begin{array}{l}\text { Solution } \\
\text { time } \\
(\mathrm{min})\end{array}$ & $\begin{array}{l}\mathrm{N}^{\circ} \text { used } \\
\text { transport }\end{array}$ & $\mathrm{N}^{\circ}$ paths \\
\hline \multirow[t]{3}{*}{ hptoptw-j11a } & $\alpha$ & 286.5 & 89 & 795.86 & 9 & 0.42 & 3 & 2 \\
\hline & $\beta$ & 41 & 3 & 194.21 & 3 & 19.47 & 3 & 2 \\
\hline & $\gamma$ & 77 & 20 & 64.68 & 4 & 0.28 & 3 & 2 \\
\hline \multirow[t]{3}{*}{ hptoptw-j11b } & $\alpha$ & 269.5 & 93 & 771.95 & 8 & 0.3 & 3 & 2 \\
\hline & $\beta$ & 41 & 3 & 398.29 & 3 & 6.39 & 3 & 2 \\
\hline & $\gamma$ & 72.5 & 13 & 152.44 & 4 & 0.24 & 3 & 2 \\
\hline \multirow[t]{3}{*}{ hptoptw-j11c } & $\alpha$ & 149.5 & 53 & 652.07 & 5 & 0.28 & 3 & 2 \\
\hline & $\beta$ & 49 & 3 & 151.69 & 3 & 1.06 & 3 & 2 \\
\hline & $\gamma$ & 73 & 10 & 120.78 & 3 & 0.26 & 3 & 2 \\
\hline \multirow[t]{3}{*}{ hptoptw-j11d } & $\alpha$ & 135 & 26 & 563.64 & 4 & 0.37 & 3 & 2 \\
\hline & $\beta$ & 98 & 6 & 304.82 & 3 & 0.57 & 3 & 2 \\
\hline & $\gamma$ & 98 & 6 & 271.03 & 3 & 0.22 & 3 & 2 \\
\hline \multirow[t]{2}{*}{ hptoptw-j11e } & $\alpha$ & 262.5 & 66 & 1190.55 & 9 & 29.2 & 3 & 3 \\
\hline & $\gamma$ & 120.5 & 22 & 134.61 & 4 & 0.22 & 3 & 3 \\
\hline \multirow[t]{2}{*}{ hptoptw-j16a } & $\alpha$ & 443 & 120 & 1396.85 & 12 & 2.39 & 3 & 3 \\
\hline & $\gamma$ & 51 & 3 & 22.23 & 4 & 0.37 & 3 & 3 \\
\hline \multirow[t]{2}{*}{ hptoptw-j16b } & $\alpha$ & 434.5 & 110 & 1299.93 & 14 & 7.45 & 3 & 3 \\
\hline & $\gamma$ & 59.5 & 10 & 80.9 & 4 & 0.3 & 2 & 3 \\
\hline \multirow[t]{2}{*}{ hptoptw-j16c } & $\alpha$ & 304.5 & 85 & 1842.84 & 10 & 10.15 & 3 & 3 \\
\hline & $\gamma$ & 131 & 25 & 234.9 & 4 & 1 & 3 & 3 \\
\hline \multirow[t]{2}{*}{ hptoptw-j16d } & $\alpha$ & 386 & 105 & 2108.97 & 12 & 23.01 & 3 & 3 \\
\hline & $\gamma$ & 80 & 12 & 246.03 & 4 & 0.53 & 3 & 3 \\
\hline hptoptw-j16e & $\gamma$ & 129.5 & 14 & 52.46 & 5 & 0.42 & 3 & 4 \\
\hline hptoptw-j21a & $\gamma$ & 75.5 & 12 & 81.71 & 4 & 1.48 & 2 & 3 \\
\hline \multirow[t]{2}{*}{ hptoptw-j21b } & $\alpha$ & 640 & 175 & 937.68 & 19 & 81,16 & 3 & 2 \\
\hline & $\gamma$ & 46 & 5 & 50.56 & 4 & 1.03 & 2 & 3 \\
\hline \multirow[t]{2}{*}{ hptoptw-j21c } & $\alpha$ & 51 & 10 & 646.32 & 4 & 0.25 & 3 & 3 \\
\hline & $\gamma$ & 83.5 & 20 & 82.21 & 4 & 1.18 & 3 & 3 \\
\hline \multirow[t]{2}{*}{ hptoptw-j21d } & $\alpha$ & 56 & 5 & 729.71 & 4 & 0.35 & 3 & 3 \\
\hline & $\gamma$ & 90.5 & 25 & 151.46 & 5 & 1.22 & 3 & 3 \\
\hline
\end{tabular}

Consequently, the benefits obtained by tourists are diminished, showing that the three objectives conflict. The selection process of the solutions in each instance is performed by the decision-maker. The solutions must meet the Pareto dominance criteria (non-dominated solutions) (Villegas et al., 2006). In Addition, for the selection of solutions, it was necessary to analyze criteria of the behavior of the routes in terms of number of nodes visited, routes enabled, gap, solution time, and transport modes selected in contrast to the solutions given in Sects. 5.2 and 5.3. The selected solutions compared to the optimal solutions of the first objective are shown in Table 5.

Based on these criteria, in the first model, solutions with $\beta \geq 0.5$ are selected because solutions with a gap of $0 \%$ are generally obtained. Additionally, we considered solutions that had almost the same number of POIs as the optimal solution. The selected 

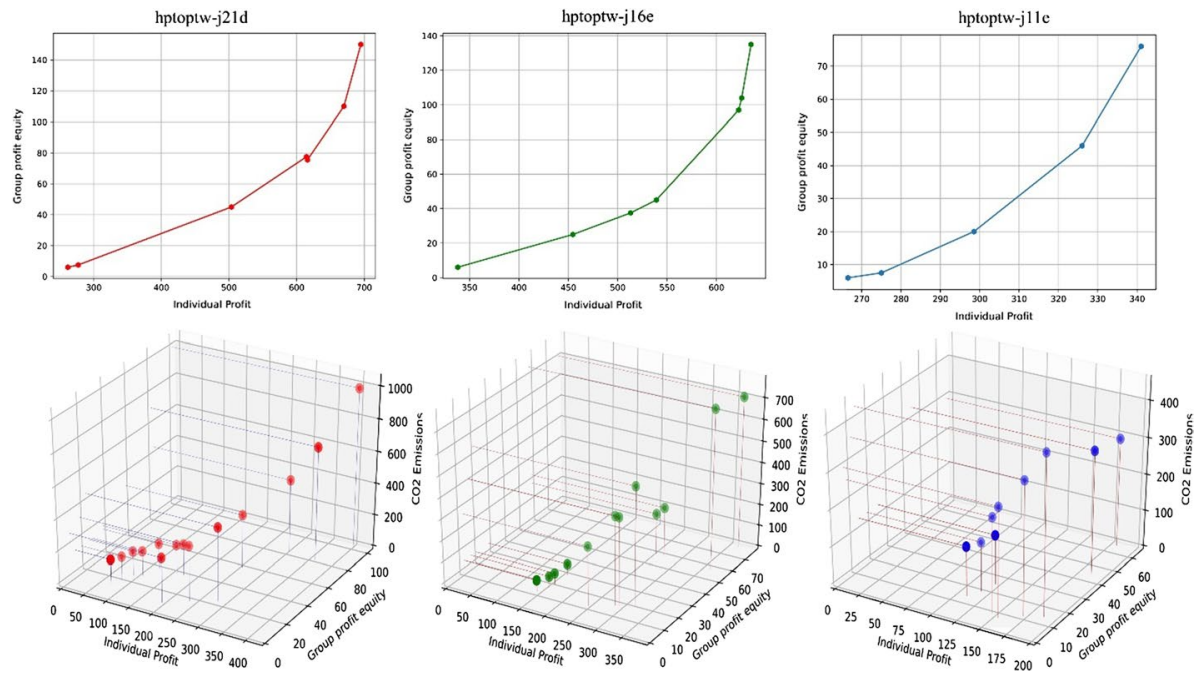

Fig. 3 Pareto frontier of hptoptw-j [11e, 16e, and 21d] instances for both models
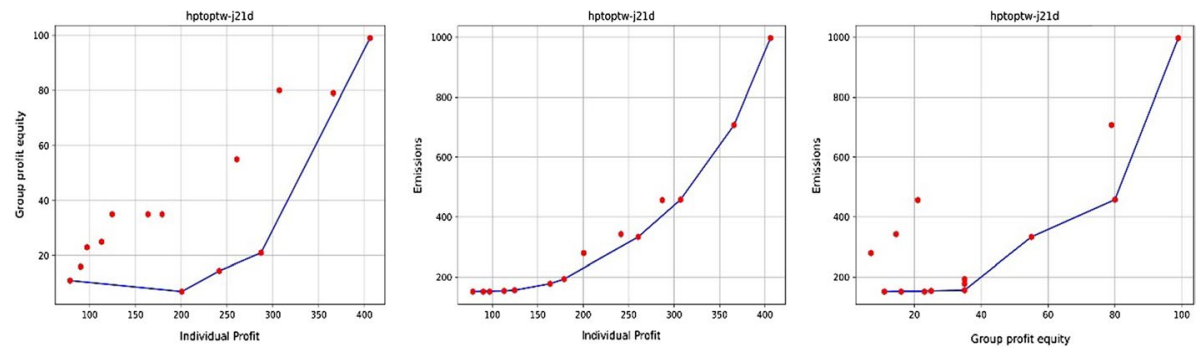

Fig. 4 Two-by-two objective comparison for hptoptw-j21d

solutions of the second model have a $\alpha \geq 0.5$ which ensures that the model gives greater importance to the individual profit objective. This objective is directly correlated to the number of POIs that compose the routes. Therefore, a higher weight of $\alpha$ generates the inclusion of a greater number of POIs. $\gamma \leq 0.2$ is selected to ensure that as many POIs as possible are included in the route. The lower the $\mathrm{CO}_{2}$ emissions, the fewer POIs are included. The aim is to allow tourists to visit as many POIs as possible without neglecting equity and minimizing emissions. In addition, priority is given to the solutions that present the smallest gap. The analysis is individual for each instance.

The selected solutions are compared with the optimal result of the solved model only for the first objective (maximize profit). Similarly, the number of POIs included in both solutions (selected and optimal) is observed. The average difference in individual profits is $14.35 \%$. The $40 \%$ of the selected solutions have the same number of POIs as the optimal route. Some even have a higher number of POIs. However, a higher number of POIs does not ensure a higher profit because it depends on the importance of those POIs for the visiting tourist (heterogeneous preferences). The solution times also vary depending on the combinations of the objective weights and the complexity of the instance. For the 


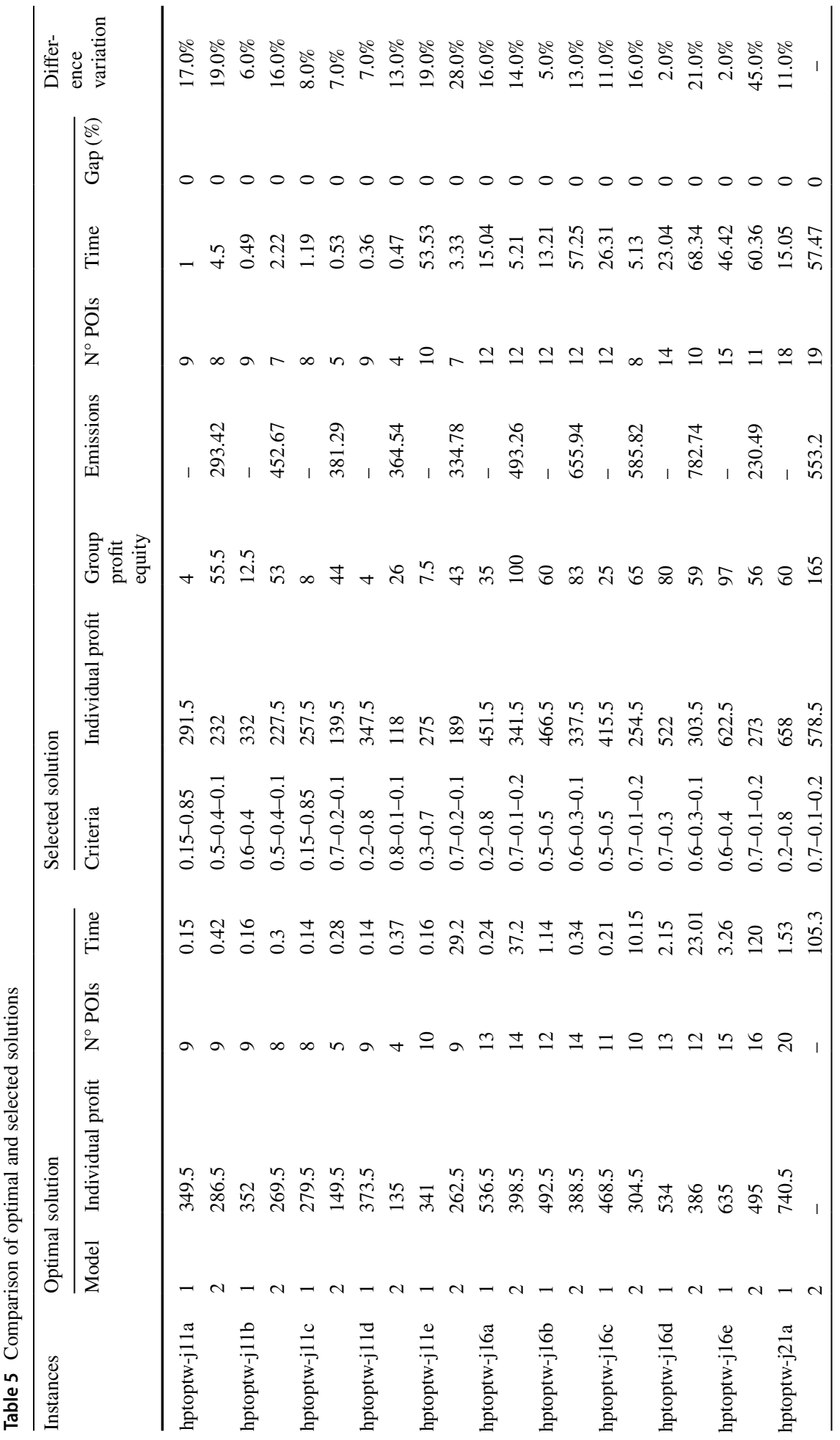




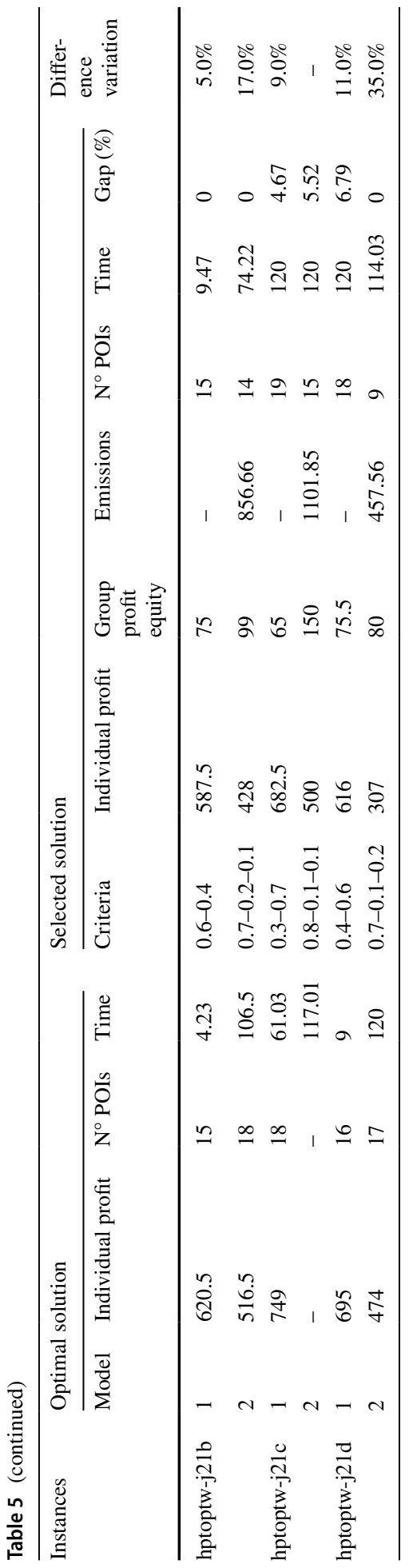


hptoptw-j21[c and d] instances, the selected solutions did not reach the $0 \%$ gap in the maximum time set for model execution (120 min).

\section{Concluding remark}

Tourism requires the application and development of different models and strategies that allow for assertive decision-making for the economic recovery generated by the current COVID-19 pandemic. Likewise, these models must contribute to the achievement of sustainable development objectives within the framework of sustainable tourism. Unlike the literature cited in Table 1, via the development of this paper, the following main contributions were made. In the first instance, two models of tourism itinerary planning were developed to maximize profit, considering two major current tourism problems. Initially, the first model considers the group travel restrictions generated by the pandemic and the selection of modes of transport, through the scheme of flexibility in the organization of routes for a tourist group based on individual preferences and equity in group profit. Therefore, the model allows for the definition of the number of tourists per group and route as well as the type of transport to be used for the trip. Later, in the second model, in addition to the aspects of the first model, the environmental implications generated by transport are considered and minimized. The second contribution of this paper concerns that the model was tested with a set of small theoretical instances that were designed because of the lack of instances for models involving individual preferences in a group. The results show that the objectives of the models are in conflict, generating direct repercussions on the number of POIs visited; in none of the solutions generated was it possible to visit all the POIs. Additionally, with the inclusion of the objective associated with the minimization of $\mathrm{CO}_{2}$, visits were substantially reduced compared to the results of the first model and the initial optimal results. Similarly, an increase in the computational solution time was observed, which leads to the need to apply approximate methods in future work to plan for scenarios that present more than 21 POIs, 7 tourists, the option of opening 4 routes, and 3 modes of transport. Thirdly, the results show that to carry out the analysis of the best solutions it is not enough to examine the Pareto frontier, but also to consider the number of POIs visited, the computational times, the gap, the number of routes, and transport modes, i.e., a generalized analysis of each group of solutions obtained in each instance. However, it was noted that the best solutions are those where the weight of the individual benefit criterion is greater than others. Fourthly, the model presents a more realistic approach that makes it computationally complex and can be contrasted by applying it to real-life tourism route design problems.

Our paper contributes to the management of more sustainable tourism itineraries from an environmental and social perspective (minimization of $\mathrm{CO}_{2}$ emissions and the contribution of social criteria based on the equity of group profit). These criteria suggest real scenarios where the tourist prefers to travel in groups but at the same time has individual preferences on some POIs and is aware of the environmental impact. Other future research lines that can be directed correspond to the inclusion of the types of tourism in the planning of the itinerary according to the typology of products and tourist activities that are offered. In the work of McKercher (2016) the tourist products are grouped in five families which are human endeavors, personal quest, nature, business, and pleasure. Similarly, it is possible to consider the construction of routes that have more than one starting point (i.e., multiple deposits). Finally, in terms of the development of approximate methods, the use 
of hybrid methods may represent an improvement approach for the solutions of this type of problems (Hapsari et al., 2019), in addition to being a novel contribution to the literature due to their scarce application in the TTDP (Ruiz-Meza \& Montoya-Torres, 2020).

Acknowledgements The work presented in this paper is partially funded under Doctoral Scholarship "Carlos Jordana" from the School of Engineering at Universidad de La Sabana (Project INGPhD-37-2020), and by a scholarship from the Colombian Ministry of Science, Technology, and Innovation.

\section{References}

Abbaspour, R. A., \& Samadzadegan, F. (2009). Itinerary planning in multimodal urban transportation network. Journal of Applied Sciences, 9(10), 1898-1906.

Abbaspour, R. A., \& Samadzadegan, F. (2011). Time-dependent personal tour planning and scheduling in metropolises. Expert Systems with Applications, 38(10), 12439-12452.

Almouhanna, A., Quintero-Araujo, C. L., Panadero, J., Juan, A. A., Khosravi, B., \& Ouelhadj, D. (2020). The location routing problem using electric vehicles with constrained distance. Computers \& Operations Research, 115, Article ID: 104864.

Bagloee, S. A., Tavana, M., Di Caprio, D., Asadi, M., \& Heshmati, M. (2017). A multi-user decision support system for online city bus tour planning. Journal of Modern Transportation, 25(2), 59-73.

Bai, C., Fahimnia, B., \& Sarkis, J. (2017). Sustainable transport fleet appraisal using a hybrid multi-objective decision making approach. Annals of Operations Research, 250(2), 309-340.

Bektaş, T., \& Laporte, G. (2011). The Pollution-Routing Problem. Transportation Research Part B: Methodological, 45(8), 1232-1250.

Brilhante, I., Macedo, J. A., Nardini, F. M., Perego, R., \& Renso, C. (2013). Where shall we go today? In Proceedings of the 22nd ACM international conference on conference on information and knowledge management (CIKM 2013) (pp. 757-762), New York, NY, USA.

Brilhante, I. R., Macedo, J. A., Nardini, F. M., Perego, R., \& Renso, C. (2015). On planning sightseeing tours with TripBuilder. Information Processing and Management, 51(2), 1-15.

Brito, J., Expósito-Márquez, A., \& Moreno, J. A. (2017). A fuzzy GRASP algorithm for solving a tourist trip design problem. In Proceedings of the 2017 IEEE international conference on fuzzy systems (FUZZ-IEEE), (pp. 1-6), Naples, Italy.

Chao, I.-M., Golden, B. L., \& Wasil, E. A. (1996). The team orienteering problem. European Journal of Operational Research, 88, 464-474.

Chaudhari, K., \& Thakkar, A. (2019). A comprehensive survey on travel recommender systems. Archives of Computational Methods in Engineering, 7, 2-12.

Daniel, A. D., Costa, R. A., Pita, M., \& Costa, C. (2017). Tourism Education: What about entrepreneurial skills? Journal of Hospitality and Tourism Management, 30, 65-72.

De Marco, A., Mangano, G., \& Zenezini, G. (2017). Classification and benchmark of City Logistics measures: An empirical analysis. International Journal of Logistics Research and Applications, 21(1), $1-19$.

Deitch, R., \& Ladany, S. P. (2000). The one-period bus touring problem: Solved by an effective heuristic for the orienteering tour problem and improvement algorithm. European Journal of Operational Research, 127(1), 69-77.

Deitch, R., \& Ladany, S. P. (2001). Determination of optimal one-period tourist bus tours with identical starting and terminal points. International Journal of Services, Technology and Management, 2(1-2), $116-129$.

Department for Business Energy and Industrial Strategy. (2019). 2019 Government Greenhouse Gas Conversion Factors for Company Reporting. Methodology Paper for Emission Factors. Retrieved from https://assets.publishing.service.gov.uk/government/uploads/system/uploads/attachment_data/file/ 829336/2019_Green-house-gas-reporting-methodology.pdf

Expósito, A., Mancini, S., Brito, J., \& Moreno, J. A. (2019a). A fuzzy GRASP for the tourist trip design with clustered POIs. Expert Systems with Applications, 127, 210-227.

Expósito, A., Mancini, S., Brito, J., \& Moreno, J. A. (2019b). Solving a fuzzy tourist trip design problem with clustered points of interest. In E. H. Cables, M. T. Lamata, \& J. L. Verdegay (Eds.), Uncertainty management with fuzzy and rough sets (Vol. 377, pp. 115-126). Springer.

Fiack, D., Cumberbatch, J., Sutherland, M., \& Zerphey, N. (2021). Sustainable adaptation: Social equity and local climate adaptation planning in U.S. cities. Cities, 115, 103235. 
Filimonau, V., Dickinson, J., \& Robbins, D. (2014). The carbon impact of short-haul tourism: A case study of UK travel to Southern France using life cycle analysis. Journal of Cleaner Production, 64, 628-638.

Garcia, A., Arbelaitz, O., Otaegui, O., Vansteenwegen, P., \& Linaza, M. T. (2009). Public transportation algorithm for an intelligent routing system. In Proceedings 16th world congress and exhibition on intelligent transport systems and services (pp. 5999-6006).

Garcia, A., Arbelaitz, O., Linaza, M. T., Vansteenwegen, P., \& Souffriau, W. (2010). Personalized tourist route generation. Lecture Notes in Computer Science (Including Subseries Lecture Notes in Artificial Intelligence and Lecture Notes in Bioinformatics), 6385 LNCS, pp. 486-497.

Garcia, A., Arbelaitz, O., Vansteenwegen, P., Souffriau, W., \& Linaza, M. T. (2010b). Hybrid approach for the public transportation time dependent orienteering problem with time windows. Lecture Notes in Computer Science, 6077, 151-158.

Garcia, A., Vansteenwegen, P., Arbelaitz, O., Souffriau, W., \& Linaza, M. T. (2013). Integrating public transportation in personalised electronic tourist guides. Computers \& Operations Research, 40(3), $758-774$.

Gavalas, D., Kasapakis, V., Pantziou, G., Konstantopoulos, C., Vathis, N., Mastakas, K., \& Zaroliagis, C. (2016). Scenic Athens: A personalized scenic route planner for tourists. In Proceedings of the 2016 IEEE symposium on computers and communication (ISCC), (pp. 1151-1156).

Gavalas, D., Kasapakis, V., Konstantopoulos, C., Pantziou, G., \& Vathis, N. (2017). Scenic route planning for tourists. Personal and Ubiquitous Computing, 21(1), 137-155.

Gavalas, D., Kasapakis, V., Konstantopoulos, C., Pantziou, G., Vathis, N., \& Zaroliagis, C. (2015a). The eCOMPASS multimodal tourist tour planner. Expert Systems with Applications, 42(21), 7303-7316.

Gavalas, D., Konstantopoulos, C., Mastakas, K., \& Pantziou, G. (2014). A survey on algorithmic approaches for solving tourist trip design problems. Journal of Heuristics, 20(3), 291-328.

Gavalas, D., Konstantopoulos, C., Mastakas, K., Pantziou, G., \& Vathis, N. (2015b). Heuristics for the time dependent team orienteering problem: Application to tourist route planning. Computers \& Operations Research, 62, 36-50.

Goodell, J. W. (2020). COVID-19 and finance: Agendas for future research. Finance Research Letters, 35, Article ID: 101512.

Gunawan, A., Lau, H. C., \& Vansteenwegen, P. (2016). Orienteering Problem: A survey of recent variants, solution approaches and applications. European Journal of Operational Research, 255(2), 315-332.

Hapsari, I., Surjandari, I., \& Komarudin, K. (2019). Solving multi-objective team orienteering problem with time windows using adjustment iterated local search. Journal of Industrial Engineering International, 15, 679-693.

Hasuike, T., Katagiri, H., Tsubaki, H., \& Tsuda, H. (2013). Interactive multi-objective route planning for sightseeing on time-expanded networks under various conditions. Procedia Computer Science, 22, 221-230.

Juan, A. A., Mendez, C. A., Faulin, J., De Armas, J., \& Grasman, S. E. (2016). Electric vehicles in logistics and transportation: A survey on emerging environmental, strategic, and operational challenges. Energies, 9(2), 1-21.

Kara, I., Bicakci, P. S., \& Derya, T. (2016). New formulations for the orienteering problem. Procedia Economics and Finance, 39, 849-854.

Kotiloglu, S., Lappas, T., Pelechrinis, K., \& Repoussis, P. P. (2017). Personalized multi-period tour recommendations. Tourism Management, 62, 76-88.

Leiper, N. (1979). The framework of tourism: Towards a definition of tourism, tourist, and the tourist industry. Annals of Tourism Research, 6(4), 390-407.

Le-Klähn, D. T., \& Hall, C. M. (2015). Tourist use of public transport at destinations-A review. Current Issues in Tourism, 18(8), 785-803.

Leong, T. Y., \& Ladany, S. P. (2001). Optimal cruise itinerary design development. International Journal of Services, Technology and Management, 2(1-2), 130-141.

Li, J., Nguyen, T., \& Coca-Stefaniak, J. A. (2020). Coronavirus impacts on post-pandemic planned travel behaviours. Annals of Tourism Research, Article ID: 102964. Advance online publication.

Liao, Z., \& Zheng, W. (2018). Using a heuristic algorithm to design a personalized day tour route in a timedependent stochastic environment. Tourism Management, 68, 284-300.

Lim, K. H., Chan, J., Karunasekera, S., \& Leckie, C. (2019). Tour recommendation and trip planning using location-based social media: A survey. Knowledge and Information Systems, 60(3), 1247-1275.

Lim, K. H., Chan, J., Leckie, C., \& Karunasekera, S. (2017). Personalized trip recommendation for tourists based on user interests, points of interest visit durations and visit recency. Knowledge and Information Systems, 54(2), 375-406.

Lin, S., \& Yu, V. (2017). Solving the team orienteering problem with time windows and mandatory visits by multi-start simulated annealing. Computers and Industrial Engineering, 114, 195-205. 
Malucelli, F., Giovannini, A., \& Nonato, M. (2015). Designing single origin-destination itineraries for several classes of cycle-tourists. Transportation Research Procedia, 10, 413-422.

Marrekchi, E., Besbes, W., Dhouib, D., \& Demir, E. (2021). A review of recent advances in the operations research literature on the green routing problem and its variants. Annals of Operations Research, 0123456789 .

McKercher, B. (2016). Towards a taxonomy of tourism products. Tourism Management, 54, 196-208.

Millán, M. (2010). Planificación: Transporte, turismo y territorio. Revista De Investigaciones Turísticas No, 1(1), 97-119.

Morana, J. (2014). Sustainable supply chain management in urban logistics. In J. Gonzalez-Feliu, F. Semet, \& J.-L. Routhier (Eds.), Sustainable urban logistics: Concepts, methods and information systems (pp. 21-35). Springer.

Muñoz-Villamizar, A., Montoya-Torres, J. R., \& Faulin, J. (2017). Impact of the use of electric vehicles in collaborative urban transport networks: A case study. Transportation Research Part D: Transport and Environment, 50, 40-54.

Muñoz-Villamizar, A., Quintero-Araújo, C. L., Montoya-Torres, J. R., \& Faulin, J. (2019). Short- and mid-term evaluation of the use of electric vehicles in urban freight transport collaborative networks: A case study. International Journal of Logistics Research and Applications, 22(3), 229-252.

Nepal, R., \& Indra al Irsyad, M., \& Nepal, S. K. . (2019). Tourist arrivals, energy consumption and pollutant emissions in a developing economy-implications for sustainable tourism. Tourism Management, 72, 145-154.

Nguyen, T. Q. T., Young, T., Johnson, P., \& Wearing, S. (2019). Conceptualising networks in sustainable tourism development. Tourism Management Perspectives, 32, Article ID: 100575.

Nicola, M., Alsafi, Z., Sohrabi, C., Kerwan, A., Al-Jabir, A., Iosifidis, C., Agha, M., \& Aghaf, R. (2020). The socio-economic implications of the coronavirus and COVID-19 pandemic: A review. International Journal of Surgery, 78, 185-193.

Perramon, J., Alonso-Almeida, M. M., Llach, J., \& Bagur-Femenías, L. (2014). Green practices in restaurants: Impact on firm performance. Operations Management Research, 7(1-2), 2-12.

Pradenas, L., Oportus, B., \& Parada, V. (2013). Mitigation of greenhouse gas emissions in vehicle routing problems with backhauling. Expert Systems with Applications, 40(8), 2985-2991.

Qian, J., \& Eglese, R. (2016). Fuel emissions optimization in vehicle routing problems with time-varying speeds. European Journal of Operational Research, 248(3), 840-848.

Rodríguez, B., Molina, J., Pérez, F., \& Caballero, R. (2012). Interactive design of personalised tourism routes. Tourism Management, 33(4), 926-940.

Ruiz-Meza, J., \& Montoya-Torres, J. R. (2020). The tourist trip design problem: Extensions, solution methods and future research lines. International Transactions in Operational Research (Submitted).

Ruiz-Meza, J., Montes, I., Pérez, A., \& Ramos-Márquez, M. (2020). VRP model with time window, multiproduct and multidepot. Journal of Applied Science and Engineering, 23(2), 239-247.

Saluveer, E., Raun, J., Tiru, M., Altin, L., Kroon, J., Snitsarenko, T., Snitsarenko, T., Aasa, A., Silm, S. (2020). Methodological framework for producing national tourism statistics from mobile positioning data. Annals of Tourism Research, 81, Article ID: 102895.

Samson, D. (2020). Operations/supply chain management in a new world context. Operations Management Research, 13, 1-3.

Sánchez, S., Green, J., Orjuela, J. P., \& Klakamp, J. (2013). Metodologías para la estimación de emisiones de transporte urbano de carga y guías para la recopilación y organización de datos. Clean Air Institute, Washington, D.C., USA.

Scott, D., Gössling, S., \& Hall, C. M. (2012). International tourism and climate change. Wires Climate Change, 3(3), 213-232.

Scott, D., Hall, C. M., \& Gössling, S. (2016). A review of the IPCC Fifth Assessment and implications for tourism sector climate resilience and decarbonization. Journal of Sustainable Tourism, 24(1), 8-30.

Scott, D., Hall, C. M., \& Gössling, S. (2019). Global tourism vulnerability to climate change. Annals of Tourism Research, 77, 49-61.

Sedarati, P., Santos, S., \& Pintassilgo, P. (2019). System Dynamics in Tourism Planning and Development. Tourism Planning and Development, 16(3), 256-280.

SENDECO2 (2020). Sistema europeo de negociación de $\mathrm{CO}_{2}$. Retrieved from Precios de $\mathrm{CO}_{2}$ website: https:// www.sendeco2.com/es/precios-co2

Shcherbina, O., \& Shembeleva, E. (2014). Modeling recreational systems using optimization techniques and information technologies. Annals of Operations Research, 221(1), 309-329.

Souffiau, W., Maervoet, J., Vansteenwegen, P., Vanden Berghe, G., \& Van Oudheusden, D. (2009). A mobile tourist decision support system for small footprint devices. Lecture Notes in Computer Science, 5517, 1248-1255.

Souffriau, W., \& Vansteenwegen, P. (2010). Trip planning functionalities: State of the art and future. Information Technology \& Tourism, 12(4), 305-315. 
Susanty, A., Puspitasari, N. B., Saptadi, S., \& Prasetyo, S. (2018). Implementation of green tourism concept through a dynamic programming algorithm to select the best route of tourist travel. In IOP conference series: Earth and environmental science, 195, Article ID: 012035.

Sylejmani, K., Dorn, J., \& Musliu, N. (2012). A Tabu search approach for multi constrained team orienteering problem and its application in touristic trip planning. In Proceedings of the 2012 12th international conference on hybrid intelligent systems (HIS 2012), (pp. 300-305). Pune, India. IEEE.

Sylejmani, K., Dorn, J., \& Musliu, N. (2017). Planning the trip itinerary for tourist groups. Information Technology and Tourism, 17(3), 275-314.

Tawfik, C., \& Limbourg, S. (2019). Scenario-based analysis for intermodal transport in the context of service network design models. Transportation Research Interdisciplinary Perspectives, 2, Article ID: 100036.

UNWTO (2012). Tourism in the Green Economy-Background Report. Organization United Nations Environment Programme and World Tourism. Madrid, Spain. https://doi.org/10.18111/9789284414529

Van Truong, N., \& Shimizu, T. (2017). The effect of transportation on tourism promotion: Literature review on application of the Computable General Equilibrium (CGE) Model. Transportation Research Procedia, 25, 3096-3115.

Vansteenwegen, P. (2009). Planning in tourism and public transportation: Attraction selection by means of a personalised electronic tourist guide and train transfer scheduling. 4 OR, 7(3), 293-296.

Vansteenwegen, P., Souffriau, W., Vanden Berghe, G., \& Van Oudheusden, D. (2009). Metaheuristics for tourist trip planning. In M. J. Geiger, W. Habenicht, \& M. Sevaux (Eds.), KennethMetaheuristics in the service industry. Lecture Notes in Economics and Mathematical Systems (Vol. 624, pp. 15-31). Berlin: Springer.

Vansteenwegen, P., \& Van Oudheusden, D. (2007). The mobile tourist guide: An OR opportunity. Or Insight, 20(3), 21-27.

Vega-Mejía, C. A., Montoya-Torres, J. R., \& Islam, S. M. N. (2019). Consideration of triple bottom line objectives for sustainability in the optimization of vehicle routing and loading operations: a systematic literature review. Annals of Operations Research, 273(1-2), 311-375.

Verbeeck, C., Vansteenwegen, P., \& Aghezzaf, E. H. (2014). An extension of the arc orienteering problem and its application to cycle trip planning. Transportation Research Part E: Logistics and Transportation Review, 68, 64-78.

Villegas, J. G., Palacios, F., \& Medaglia, A. L. (2006). Solution methods for the bi-objective (cost-coverage) unconstrained facility location problem with an illustrative example. Annals of Operations Research, 147(1), 109-141.

Wang, W., Liu, J., \& Innes, J. L. (2019). Conservation equity for local communities in the process of tourism development in protected areas: A study of Jiuzhaigou Biosphere Reserve. China. World Development, 124, 104637.

Wang, Y. W., Lin, C. C., \& Lee, T. J. (2018). Electric vehicle tour planning. Transportation Research Part D: Transport and Environment, 63(May), 121-136.

WTO (2019). International tourism highlights, world tourism organization, 2019 Edition. https://doi.org/10. $18111 / 9789284421152$

Wu, X., Guan, H., Han, Y., \& Ma, J. (2017). A tour route planning model for tourism experience utility maximization. Advances in Mechanical Engineering, 9(10), 1-8.

Yu, J., Aslam, J., Karaman, S., \& Rus, D. (2015). Anytime planning of optimal schedules for a mobile sensing robot. In Proceedings of the IEEE international conference on intelligent robots and systems (pp. 5279-5286).

Yu, V. F., Jewpanya, P., Ting, C.-J., \& Redi, A. A. N. P. (2017). Two-level particle swarm optimization for the multi-modal team orienteering problem with time windows. Applied Soft Computing, 61, 1022-1040.

Yuan, J., Deng, J., Pierskalla, C., \& King, B. (2018). Urban tourism attributes and overall satisfaction: An asymmetric impact-performance analysis. Urban Forestry \& Urban Greening, 30, 169-181.

Zeng, S. X., Meng, X. H., Yin, H. T., Tam, C. M., \& Sun, L. (2010). Impact of cleaner production on business performance. Journal of Cleaner Production, 18(10-11), 975-983.

Zheng, W., Huang, X., \& Li, Y. (2017). Understanding the tourist mobility using GPS: Where is the next place? Tourism Management, 59, 267-280.

Zheng, W., Ji, H., Lin, C., Wang, W., \& Yu, B. (2020). Using a heuristic approach to design personalized urban tourism itineraries with hotel selection. Tourism Management, 76(422), 103956.

Zheng, W., \& Liao, Z. (2019). Using a heuristic approach to design personalized tour routes for heterogeneous tourist groups. Tourism Management, 72(555), 313-325.

Publisher's Note Springer Nature remains neutral with regard to jurisdictional claims in published maps and institutional affiliations. 